\title{
USO DO PEERWISE COMO FERRAMENTA PEDAGÓGICA NAS DISCIPLINAS DE SOLOS DA ENGENHARIA CIVIL
}

Vitoria J. S. Silva - jessica.oria@ hotmail.com

Mariana V. Silveira - mvsilveira@ufc.br

Universidade Federal do Ceará

Ac. Público, 713 - Pici

60020-181 - Fortaleza - CE

Resumo: O PeerWise é uma ferramenta on-line que permite aos alunos criar, explicar e enviar suas próprias perguntas de múltipla escolha e compartilhá-las com seus colegas de classe formando um banco de questões. O objetivo deste estudo é avaliar o envolvimento dos alunos das disciplinas Fundações e Mecânica dos solos do curso de engenharia civil com a ferramenta PeerWise. A implementação do PeerWise nas disciplinas ocorreu de forma optativa e pré-estabelecida no primeiro dia de aula em ambas as disciplina. Para tanto, foi requerido aos alunos que realizassem um número mínimo de atividades no PeerWise semanalmente ao longo do semestre e que ao término das disciplinas respondessem um questionário online acerca da sua experiência pessoal com a ferramenta. Ao final do semestre verificou-se que a ferramenta cumpriu com o propósito de ser uma alternativa para os alunos exercitarem os conhecimentos adquiridos em sala de aula sendo utilizada com maior frequência nas vésperas das avaliações parciais.

Palavras-chave: Questões de múltipla escolha. Aprendizagem colaborativa. Banco de questões. Revisão da matéria.

\section{INTRODUÇÃO}

É de conhecimento geral que os procedimentos de ensino, dentro do processo de aprendizagem, são tão importantes para construção do conhecimento quanto o próprio conteúdo abordado logo, a abordagem de ferramentas diversas que incentivem a aprendizagem são necessárias no ambiente acadêmico (KELLEY et al, 2019).

Esse é o caso do PeerWise, uma ferramenta online que incentiva a aprendizagem colaborativa e independente, facilitando aos alunos a criação e o compartilhamento de perguntas de múltipla escolha relevantes para a sua área de estudo em conjunto com uma explicação/resolução formando um banco de questões (OGAWA et al, 2015). Os outros alunos do mesmo curso podem acessar este banco de questões e usar as perguntas para a sua auto-avaliação, aprender com as explicações, avaliar a qualidade das perguntas disponíveis (usando uma escala do próprio PeerWise) e deixar comentários nas perguntas.

Um grande número de universidades em todo o mundo têm empregado o PeerWise em seus cursos como uma ferramenta de aprendizagem colaborativa. Há relatos na literatura de seu emprego nos cursos de Química, Física, Pedagogia, Enfermagem, Medicina, entre outros (e.g., DURET et al, 2018; KELLEY et al, 2019; KAY et al, 2020). Conhecendo as potencialidades desta ferramenta online, a implementação do PeerWise nas disciplinas de 
solos do curso de Engenharia Civil incentivará o desenvolvimento de habilidades cognitivas de alto nível e aprimorará o aprendizado dos alunos.

Neste contexto, o objetivo deste estudo é investigar o envolvimento dos alunos com a ferramenta PeerWise e relatar a experiência da implementação desta nas disciplinas de Fundações e de Mecânica dos solos do curso de Engenharia Civil.

\section{METODOLOGIA}

Este estudo foi desenvolvido no primeiro semestre de 2019 nas disciplinas de Fundações e Mecânica dos Solos II do curso de Engenharia Civil da Universidade Federal do Ceará. A implementação do PeerWise nas disciplinas ocorreu de forma optativa e pré-estabelecida no primeiro dia de aula em ambas as disciplinas, onde o professor orientador apresentou a ferramenta, sua forma de utilização e o objetivo do processo para os alunos

Para tanto, foi requerido aos alunos que realizassem um número mínimo de atividades no PeerWise semanalmente ao longo do semestre. O pacote de atividades envolvia elaborar 1 questão de múltipla escolha (enunciado da questão, alternativas, e gabarito) sobre o tema de estudo da semana, responder 3 questões inseridas no banco de questões pelos colegas de turma e fazer 1 comentário em uma das questões respondidas. Além disso, cada vez que uma pergunta é respondida, o PeerWise oferece ao aluno a oportunidade de classificá-la em uma escala de 6 pontos, de 0 a 5 . Isso permite que o aluno aplique seus próprios julgamentos e faça uma medida subjetiva da qualidade geral das perguntas disponibilizadas.

De forma a incentivar os alunos a participarem das atividades semanalmente foi determinada uma pontuação extra nas avaliações parciais das disciplinas para os mais participativos e que as avaliações parciais da disciplina teriam questões provenientes da ferramenta, ou seja, questões elaboradas pelos próprios alunos.

Ao término do semestre foi solicitado aos alunos que respondessem um questionário online acerca da sua experiência pessoal com a ferramenta.

O envolvimentos dos alunos com o uso da ferramenta PeerWise foi avaliado pela professora e pela aluna monitora da disciplina analisando quantitativamente e qualitativamente as interações que aconteceram semanalmente ao longo do semestre bem como pelo formulário de questionamentos proposto para os alunos ao final do semestre

\section{RESULTADOS}

\subsection{Analise quantitativa das interações na disciplina de Fundações.}

A disciplina de Fundações contava com 46 alunos matriculados, 38 deles contribuíram com pelo menos uma das atividades propostas no PeerWise durante o semestre, e somente 11 deles cumpriram com pelo menos $75 \%$ da proposta semanal de atividades.

A disciplina de Fundações contou com 12 semanas de apresentação de conteúdo e contabilizou 302 questões elaboradas, 2317 respostas submetidas e 763 comentários realizados.

Alguns alunos participaram realizando mais atividades do que foi solicitada pela proposta. Quanto a elaboração da questão de múltipla escolha 5 alunos elaboraram mais de 12 questões ao final do semestre com 2 deles elaborando 20 questões cada. O número de respostas submetidas contou com 22 alunos respondendo mais de 36 questões e 6 deles chegaram a responder mais de 100 questões cada ao longo do semestre. Quanto aos comentários, 21 alunos realizaram mais de 12 comentários e 1 aluno contribuiu com mais de 100 comentários. 


\subsection{Analise quantitativa das interações na disciplina de Mecânica dos Solos II}

A disciplina de Mecânica dos Solos II contava com 37 alunos matriculados, 32 deles contribuíram com pelo menos uma das atividades propostas no PeerWise durante o semestre, e somente 6 deles cumpriram com pelo menos $75 \%$ da proposta semanal de atividades.

A disciplina de Mecânica dos Solos II contou com 13 semanas de apresentação de conteúdo e contabilizou 306 questões elaboradas, 4162 respostas submetidas e 584 comentários realizados.

Alguns alunos participaram realizando mais atividades do que foi solicitada pela proposta. Quanto a elaboração da questão de múltipla escolha 7 alunos elaboraram mais de 13 questões ao final do semestre com 3 deles elaborando mais de 20 questões cada. $\mathrm{O}$ número de respostas submetidas contou com 24 alunos respondendo mais de 39 questões e 16 deles chegaram a responder mais de 100 questões cada ao longo do semestre. Quanto aos comentários, 12 alunos realizaram mais de 13 comentários e 4 alunos contribuíram com mais de 60 comentários.

\subsection{Analise qualitativa das interações nas duas disciplinas}

A Figura 1 foi extraída do PeerWise e apresenta o número de respostas submetidas por dia ao longo do semestre na disciplina de Mecânica dos Solos II onde foram realizadas quatro avaliações parciais. É possível observar a grande procura por esta ferramenta nos dias próximos a estas avaliações, ou seja, os alunos usaram voluntariamente o sistema PeerWise durante o período do estudo para as avaliações parciais como recurso de revisão, o que tornou a utilização do PeerWise maior nesses períodos assim como aumentou o número de questões respondidas. Este comportamento dos alunos de responderem mais perguntas do que o necessário também foi constatado por Denny et al. (2008).

Figura 1 - Número de respostas submetidas por dia na disciplina de Mecânica dos Solos II

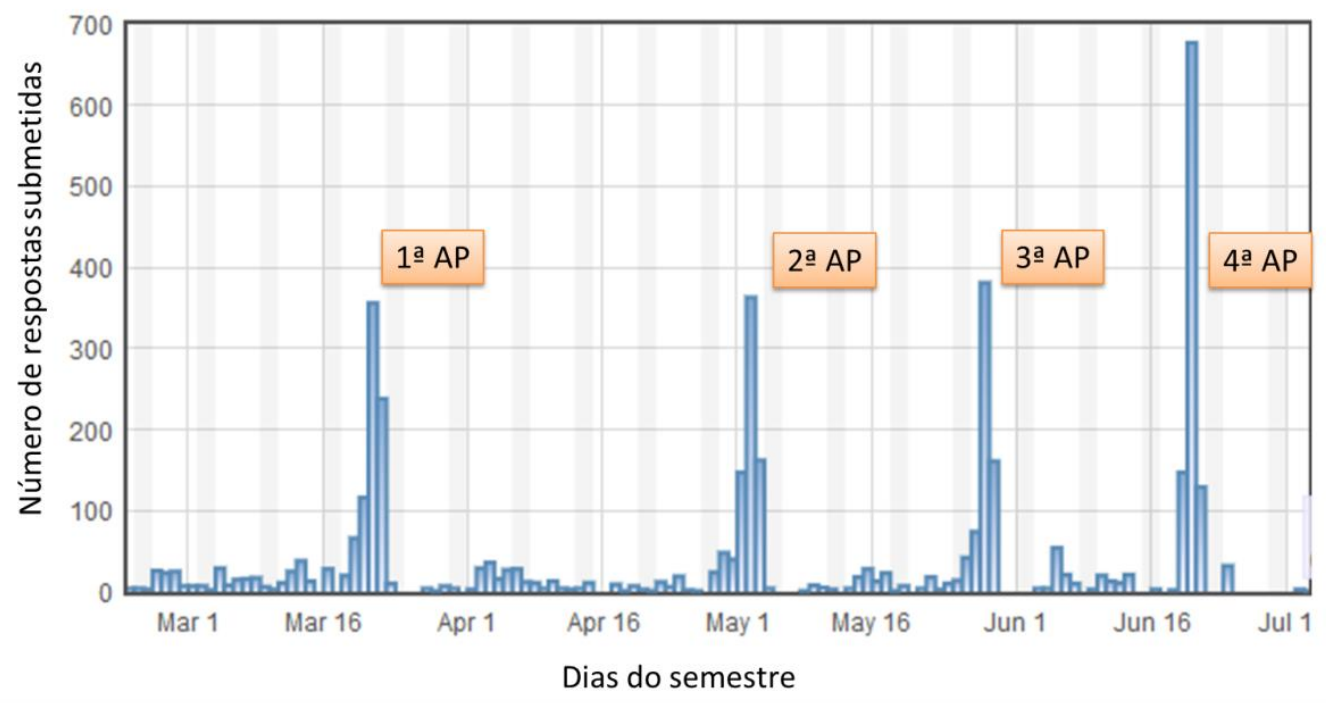

Fonte: Autores, 2020

O conhecimento do fato de que as questões da avaliação parcial viriam do banco de questões do Peerwise pode também ser usado como justificativa para este comportamento. Renzo (2014) também aponta que alguns alunos se sentem desafiados pela proposta de 
gamificação que esta ferramenta apresenta, já que o PeerWise tem um sistema de "rank" que classifica os alunos pelo grau de interação que eles tem na plataforma.

Os autores observaram a preferência por parte dos alunos pela inserção de questões teóricas na ferramenta em detrimento de questões que envolvessem cálculos e que boa parte das questões foram elaboradas pelos próprios alunos, tendo como base a aula e os slides apresentados pela professora da disciplina. Constatou-se ainda a inserção de questões por parte dos alunos provindas de livros, concursos públicos e de exames do ENADE (Exame Nacional de Desempenho dos Estudantes) anteriores.

A exigência do comentário como atividade semanal tinha como proposta fazer com que os alunos se aprofundassem no tema de estudo em que a questão estava atrelada por meio de interações e discussões. No entanto, na maioria das vezes, os alunos se manifestaram avaliando a questão, ou agradecendo pela questão bem feita ou afirmando que a mesma estava dentro do contexto da matéria daquela semana.

\subsection{Analise das respostas do formulário}

O questionário online aplicado ao final das disciplinas foi uma ferramenta de feedback onde os discentes puderam avaliar a ferramenta e fazer sugestões para empregos futuros Os resultados apresentados indicam um alto índice de aprovação do uso da ferramenta PeerWise em ambas as disciplinas As sugestões mais recorrentes são dirigidas a frequência com que as atividades são solicitadas e a seu método avaliativo. Quanto a esse último, foi sugerido pelos alunos que a utilização da ferramenta PeerWise nas disciplinas fosse tida como avaliação de mesmo peso das avaliações habituais ao invés de ser uma bonificação.

\section{CONSIDERAÇÕES FINAIS}

Este trabalho avaliou a utilização de uma ferramenta online que permite a criação de um banco de questões de múltiplas escolhas pelos próprios alunos, chamada PeerWise, nas disciplinas de solos do curso de engenharia civil. Os resultados sugerem que houve diferentes graus de envolvimento dos alunos com o PeerWise, com alguns nem mesmo acessando a plataforma e outros interagindo com mais intensidade do que foi acordado inicialmente. As questões inseridas pelos alunos tiveram origens as mais diversas o que enriquece o processo de aprendizado. Desta forma, conclui-se que a ferramenta cumpriu com o proposito de ser uma alternativa para os alunos exercitarem os conhecimentos adquiridos em sala de aula.

\section{Agradecimentos}

Os autores desejam expressar sua gratidão a Universidade Federal do Ceará pela bolsa de iniciação a docência para desenvolver este projeto.

\section{REFERÊNCIAS}

DENNY, P; LUXTON-REILLY, A; HAMER, J. Student use of the PeerWise system. In ITiCSE '08: Proceedings of the 13th annual conference on Innovation and technology in computer science education, pages 73-77, Madrid, Spain, July 2008.

DURET, D; CHRISTLEY, R; DENNY, P; SENIOR, A. Collaborative learning with PeerWise. Research in Learning Technology. v. 26, 2018. 
KAY, A; HARDY, J; GALLOWAY, R. Student use of PeerWise A multi institutional, multidisciplinary evaluation. British Journal of Educational Technology, v. 51, n. 1, 2020.

KELLEY, M; CHAPMAN-ORR, E; CALKINS, S; LEMKE, R. Generation and retrieval practice effects in the classroom using PeerWise. Teaching of Psychology, v. 46, n. 2, p. 121$126,2019$.

OGAWA, A; MAGALHÃES, G; KLOCK, A; GASPARINI, I. Análise sobre a gamificação em Ambientes Educacionais. Novas Tecnologias na Educação, v. 13, n. 12, 2015.

RENZO, A. Multiple-choice questions in the Humanities: a case study of Peerwise in a firstyear Popular Music course. In B. Hegarty, J. McDonald, \& S.-K. Loke (Eds.), Rhetoric and Reality: Critical perspectives on educational technology. Proceedings ascilite Dunedin, 2014.

\title{
USE OF PEERWISE AS A PEDAGOGICAL TOOL IN CIVIL ENGINEERING SOIL DISCIPLINES
}

\begin{abstract}
PeerWise is an online tool that allows students to create, explain and submit their own multiple-choice questions and share them with their classmates by forming a question pool. The aim of this study is to evaluate the involvement of students in the Foundations and Soil Mechanics disciplines of the civil engineering course with the PeerWise tool. The implementation of PeerWise in the disciplines took place in an optional and pre-established way on the first day of class in both disciplines. To this end, students were required to perform a minimum number of activities on PeerWise weekly throughout the semester and to complete an online questionnaire about their personal experience with the tool at the end of the courses. At the end of the semester it was found that the tool fulfilled the purpose of being an alternative for students to exercise the knowledge acquired in the classroom, being used more frequently on the days before the partial assessments.
\end{abstract}

Keywords: Multiple choice questions. Collaborative learning. Pool of questions. Review of the matter. 